\title{
$\widehat{A}$ Madridge \\ madridge Journal of Dentistry and Oral Surgery \\ Interconnecting Scientific World
}

Research Article

Open Access

\section{Parental Knowledge and Attitudes Toward Dental Trauma and Prevention in Handball and Basketball Athletes in Rijeka, Croatia}

\author{
Gregoric $\mathrm{S}^{1}$, Vranic $\mathrm{ND}^{2}$, Bakarcic $\mathrm{D}^{1}$, and Ivancic Jokic ${ }^{1 *}$ \\ ${ }^{\prime}$ School of Medicine, Department of Paediatric Dentistry, University of Rijeka, Clinical Hospital Center Rijeka, Kresimirova 40, Rijeka, Croatia \\ ${ }^{2}$ School of Dental Medicine, Department of Pediatric Dentistry, University of Zagreb, Zagreb, Croatia
}

\section{Article Info}

*Corresponding author:
Ivancic Jokic
Associate professor
School of Medicine
Department of Paediatric Dentistry
University of Rijeka
Kresimirova 40, Rijeka
Croatia
E-mail: natasa.ivancic.jokic@medri.uniri.hr

Received: July 11, 2016

Accepted: July 19, 2016

Published: July 24, 2016

Citation: Gregoric S, Vranic ND, Bakarcic D, Ivancic Jokic N. Parental knowledge and Attitudes Toward Dental Trauma and prevention in Handball and Basketball Athletes in Rijeka, Croatia. Madridge J Dent Oral Surg. 2016; 1(1): 1-3.

doi: $10.18689 / \mathrm{mjdl}-1000101$

Copyright: (c) 2016 The Author(s). This work is licensed under a Creative Commons Attribution 4.0 International License, which permits unrestricted use, distribution, and reproduction in any medium, provided the original work is properly cited.

Published by Madridge Publishers

\begin{abstract}
The aim of this study was to investigate parental knowledge and attitudes about emergency treatment of avulsed teeth, the potential of using mouth guards during children's sports, and the importance of education on this subject. Method and materials. This study was conducted on a sample size of 127 parents of athletes 8-15 years old, who were all members of handball and basketball teams in Rijeka, Croatia. Results. Approximately $68 \%$ of parents had not received education about dental injuries and were not informed about it. A small proportion of the children wore mouth guards, regardless of whether their parents were educated in terms of dental trauma or not. In the analysis of emergency procedure method used on avulsed tooth, no statistically significant difference was found between those who were previously educated about dental trauma and those who were not. Conclusion. Mouth guards should definitely become part of the mandatory equipment in sports, and this awareness should be raised in athletes as well as their parents. It is necessary to educate the public about emergency procedures in the event of dental injury.
\end{abstract}

Keywords: Dental Trauma; Knowledge; Attitude; Mouth Guard Use.

\section{Introduction}

Dental trauma is a serious health problem that is steadily increasing in recent decades [1]. Among the factors that poses the greatest risk of dental trauma is that of sport injury. Playing sports is away of promoting health as well as a powerful instrument for the promotion of social skills. However, when an athlete is injured, the consequences include emotional stress and frustration [2]. Anyone who participate in sports activities have a risk for dental injuries [3]. One of the most important classification of sports is the relative risk categories for acute injuries, as follows: contact, medium, and non-contact [4]. Handball and basketball are sports in which players are in close contact with the ball, and these sports are very common and popular in Croatia.

Handball is a risky sport with a specific mechanism of injury. Dental injuries can be caused by blows to the face by the hands and elbows or by collision with opposing players in high-speed, strong physical impact during the game. Furthermore, the ball is able to attain a great speed in a short distance and can hit players in the face, becoming another cause of trauma [5]. In basketball, the etiology of dental injuries is the same as in handball [6].

To prevent dental trauma, mouth guards are used. Correctly made mouth guards, in many cases, reduce the frequency and severity of injuries $[3,7]$. 
In amateur and recreational sports, mouth guards are not worn often, while for professionals, it depends on the level of contact of the sport.

The group with higher risk for dental trauma is that of school-age children between 7 and 15 years of age [1].

The aim of this study was to investigate parental knowledge and attitudes about emergency treatment of avulsed teeth, the potential of using mouth guards during children's sports, and the importance of education on this subject. Such study has not yet conducted among players' parents in Croatia.

\section{Materials and Methods}

This study was conducted on a sample size of 127 parents of athletes 8-15 years old (mean age was 12.19 years), who were all members of handball and basketball teams in Rijeka, Croatia. The study was approved by the Ethical Committee of the School of Medicine, University of Rijeka. Participation in the study was voluntary and confidential, and informed consent was obtained. Parents were asked to complete a questionnaire and the data gathered in this way were statistically evaluated. The questionnaire had three sub divisions, as follows: dental trauma emergency treatment, use of mouth guards, and education on dental trauma.

The data were analyzed using SAS System version 8.2 (SAS Institute Inc., North Carolina, USA). The Chi-square, Fisher's exact and Phi coefficient tests were used, and the significance level was $p<0.05$.

\section{Results}

Table 1: Additional information about dental injuries

\begin{tabular}{|c|c|c|c|c|}
\hline $\begin{array}{c}\text { Information } \\
\text { disseminated by: }\end{array}$ & \% Educated & $\begin{array}{c}\text { \% Non- } \\
\text { educated }\end{array}$ & $\mathrm{p}<$ & Phi \\
\hline Dentist & 79 & 34 & 0.001 & 0.39 \\
\hline Coach & 17 & 4 & 0.029 & 0.22 \\
\hline Parents of other children & 38 & 16 & 0.013 & 0.22 \\
\hline Literature & 17 & 0 & 0.001 & 0.37 \\
\hline Internet & 38 & 13 & 0.003 & 0.27 \\
\hline
\end{tabular}

When asked about the type of contact involved in the sport in which their children were engaged, $73 \%$ of parents had perception that their particular sport had a large amount of contact, while $27 \%$ thought that it was a medium-contact sport. The number of educated parents who had prior knowledge of dental trauma was significantly higher in comparison with those who were subsequently informed about such injuries as well as those who had no knowledge at all (Table 1.) Approximately $68 \%$ of educated parents had not received education about dental injuries and were not informed about this type of traumatic injuries at all.

Parents who believed they were sufficiently informed about dental trauma were more likely to use all sources of information concerning these types of injuries, compared with those who believed they were not sufficiently informed. In particular, parents who believed they were sufficiently informed claimed that they consulted an expert $(p<0.001$, Phi $=0.51$ ), conversations with parents of other children about these types of injuries ( $p=0.005$, Phi $=0.25$ ) and used the internet to gather information ( $p<0.001$, Phi $=0.36)$. One out of five parents who thought they were not informed about dental trauma was not even interested in learning about this type of injury as a potential concern.

The willingness of parents to broaden their knowledge demonstrated that parents were interested in acquiring further information from a dentist (Table 2.).

Table 2: Willingness to broaden knowledge base and type of education

\begin{tabular}{|c|c|c|c|c|}
\hline & \% Educated & $\begin{array}{c}\text { \% Non- } \\
\text { educated }\end{array}$ & $\mathrm{p}$ & Phi \\
\hline $\begin{array}{c}\text { Belief that education is } \\
\text { very important }\end{array}$ & 91 & 70 & $=0.011$ & 0.26 \\
\hline $\begin{array}{c}\text { Willingness to broaden } \\
\text { knowledge base }\end{array}$ & 95 & 73 & $=0.002$ & 0.28 \\
\hline $\begin{array}{c}\text { Unwillingness to broaden } \\
\text { knowledge base }\end{array}$ & 4 & 21 & $<0.001$ & 0.39 \\
\hline Type of education & & & & \\
\hline Lectures given by dentists & 57 & 27 & $<0.001$ & 0.39 \\
\hline Literature & 7 & 17 & $<0.001$ & 0.39 \\
\hline Internet & 27 & 34 & $<0.001$ & 0.39 \\
\hline
\end{tabular}

A small proportion of the children wore mouth guards, regardless of whether their parents were educated and were educated in terms of dental trauma (7\%) or not (2\%).

Among educated parents who had acquired some knowledge of dental trauma, $45 \%$ of them were not informed of the possibility that their children could wear a mouth guard. Every other parent who consulted a specialist, such as a dentist or a doctor about dental trauma, was not aware of the possibility that their child could wear a mouth guard. Among parents whose children had dental injuries, $47 \%$ did not know where they could buy or make one. Educated parents who had some information on dental trauma were also informed about where they could buy or make mouth guard (Table 3.).

Table 3: Percent of parents who are informed about where to obtain mouth guards

\begin{tabular}{|c|c|c|c|c|}
\hline & \% Educated & \% Non-educated & $\mathrm{p}$ & Phi \\
\hline Where to obtain mouth guards & 62 & 30 & $=0,002$ & 0.28 \\
\hline Type of mouth guard & 28 & 12 & $=0,077$ & 0.17 \\
\hline
\end{tabular}

Most parents who have consulted with an expert about dental trauma know where to buy the mouth guard or make them (66\%), compared with $31 \%$ of those who did not consult with an expert $(p<0.001$; Phi $=0.34)$. Parents who were informed that their children could wear a mouth guard more often have had a child with a dental trauma and are more often informed about when consulting with a dentist or doctor than those who are not informed $(60 \%$ to $35 \%$; $p=$ 0.007, Phi $=0.24$ ), and much more often than those who received information from talking to friends, parents, and children (32\% to $15 \% ; p=0.025$, Phi $=0.20$ ) or consulting the internet $(26 \%$ to $15 \% ; p=0.022$, Phi $=0.20)$. The percentage of parents who have discussed dental trauma with parents of other children were significantly larger than that of those who know where mouth guard can be purchased or made as well as that of parents without this knowledge (32\% to $15 \%$; $p=$ 0.025, Phi $=0.20$ ).

Among parents who believe in the importance of education about dental trauma as many as $61 \%$ were not aware of the fact that that their child could wear a mouth guard. In addition, $73 \%$ of those who had higher formal education had never 
formally been taught about dental trauma, and $46 \%$ were not informed about dental trauma at all.

Among these parents, a significantly higher proportion consulted a specialist concerning dental trauma(51\%) compared with those who think this type of education is not important or is only partially important (19\%) ( $p=0.004$, Phi $=0.25$ ) (Table 4).

Table 4: Parental ways of getting information

\begin{tabular}{|c|c|c|c|c|}
\hline & \% Informed & $\begin{array}{c}\text { \% Non- } \\
\text { informed }\end{array}$ & $\mathrm{p}$ & Phi \\
\hline Consultation with a dentist & 60 & 35 & $=0.007$ & 0.24 \\
\hline Conversation with friends & 32 & 15 & $=0.025$ & 0.20 \\
\hline Internet & 26 & 15 & $=0.022$ & 0.20 \\
\hline
\end{tabular}

In the analysis of emergency procedure method used on avulsed tooth, no statistically significant difference was found between those who were previously educated about dental trauma and those who were not. One out of ten parents (10\%) who had attained some knowledge about dental trauma had held the entire tooth that had been knocked out after the injury of their child, while $86 \%$ held only the crown of the tooth; additionally, $66 \%$ stated that they would place the tooth on a clean handkerchief or gauze, while $10 \%$ would wash it in water. Those who had consulted with dentist or a doctor significantly differed in their approach to handle with an avulsed tooth after injury (Table 5).

Table 5: Ways of receiving avulsed tooth

\begin{tabular}{|c|c|c|c|c|}
\hline & $\begin{array}{c}\text { \% Consult } \\
\text { the dentist }\end{array}$ & $\begin{array}{c}\text { \% Not consulting } \\
\text { the dentist }\end{array}$ & $\mathrm{p}$ & Phi \\
\hline Tooth crown & 88 & 66 & $=0.007$ & 0.29 \\
\hline Whole tooth & 9 & 21 & $=0.007$ & 0.29 \\
\hline Would not touch it & 2 & 13 & $=0.007$ & 0.29 \\
\hline
\end{tabular}

Most parents would place the tooth on a clean handkerchief or gauze (63\%). Those who had consulted a dentist or a doctor significantly differed in the manner that they treated the avulsed tooth after injury.

\section{Discussion}

Dental trauma is an emergency and requires a rapid response; any delay reduces the chance of successful treatment [8]. Handball and basketball are among contact sports with high level of contact; therefore, protection via a mouth guard and good education for emergency treatment should be provided to coaches, parents and athletes.

The results show that parents have poor awareness about wearing a mouth guard. The similar results were found in studies of Biagi in Italy and Ozer at all in Turkey $[9,10]$. Whitlam stated that it is essential that parents receive written instructions on the use of mouth guards as part of the mandatory or recommended equipment for participation in certain sports [11].

Every other parent who believed that they were informed about dental trauma was not aware that their child could wear a mouth guard, while $71 \%$ were informed about the types of mouth guard. This result allows us to conclude that dentists should better educate patients and their parents about the possibility of making and carrying mouth guards. $20 \%$ parents who thought that they were educated about dental trauma was actually not advised of the possibility of carrying mouth guards; this is an indication that education must be conducted to all levels of society on the possibilities of prevention of dental trauma.

This study shows that $75 \%$ of parents would held a tooth for a crown in the event of an injury, and 63\% would place it on a handkerchief or clean gauze. Similar results were also obtained in a study in of Raphael et al.; and Loo. et al. [12,13].

Parents should be informed about the possible complications of dental trauma that can ultimately lead to loss of a permanent tooth [14]. It is especially important that information and education concerning the prevention of dental trauma should be implemented in amateur teams, with the highest focus placed on younger age groups, to reduce potential injuries [5].

\section{Conclusion}

Mouth guards should definitely become part of the mandatory equipment in sports, and this awareness should be raised in athletes as well as their parents. It is necessary to educate the public about emergency procedures in the event of dental injury.

\section{References}

1. Mestrovic S, Gabric P D, Anic M S, Ribaric D. Risk Factors of Traumatic Injuries to the Upper Incisors. ActaStomatol Croat. 2008; 42(1): 3-10.

2. Brzic D. Causes and prevention of injuries in professional and recreational sports. [graduate thesis]. Medical faculty, University of Zagreb 2012.

3. Kumamoto $D$, Maeda $Y$. Are mouth guards necessary for basketball? $J$ Calif Dent Assoc. 2005; 33(6): 463-70.

4. Stephen G R. Medical Conditions Affecting Sports Participation. American Academy of Pediatrics. 2008; 121(4): 841-848.

5. Lang $B$, Pohl $Y$, Fillippi A. Knowledge and prevention of dental trauma in team handball in Switzerland and Germany. Dental Traumatology. 2002; 18(6): 329-334.

6. Perunski $S$, Lang B, Pohl Y, Filippi A. Level of information concerning dental injuries and their prevention in Swiss basketball - a survey among players and coaches. Dent Traumatol. 2005; 21(4): 195-200. doi: 10.1111/j.1600-9657.2005.00310.x

7. Koch G, PoulsenS. Pediatric Dentistry-a clinical approach. Blackwell:Munskgaard; 2001.

8. Grgurevic J. Traumatic tooth injuries. Sonda. 2002; 4-6.

9. Biagi R, Cardarelli F, Butti A C, Salvato A. Sports-related dental injuries: knowledge of first aid and mouthguard use in a sample of Italian children and youngsters. Eur J Paediatr Dent. 2010; 11(2): 66-70.

10. Ozer S, Yilmaz E I, Bayrak S, Tunc E S. Parental knowledge and attitudes regarding the emergency treatment of avulsed teeth. Eur J Dent. 2012; 6(4): 370-375.

11. Whitlam P. Case law in physical education and school sport. British Association of Adviser and Lectures in Physical Education; 2005.

12. Raphael SL, Gregory P J. Parental awareness of the emergency management of avulsed teeth in children. Aust Dent J. 1990; 35(2): 130-3.

13. Loo T J, Gurunathan D, Somasundaram S. Knowledge and attitude of parents with regard to avulsed permanent tooth of their children and their emergency management-- Chennai. J Indian Soc Pedod Prev Dent. 2014; 32(2): 97-107.

14. Casamassimo P S, Fields H W, McTigue J D, Nowak A. Pediatric Dentistry. Elsevier Health Sciences; 2012. 